\title{
Self-reported symptoms and healthcare seeking in the general population -exploring "The Symptom Iceberg"
}

Sandra Elnegaard ${ }^{1 *}$, Rikke Sand Andersen², Anette Fischer Pedersen ${ }^{2}$, Pia Veldt Larsen ${ }^{1}$, Jens Søndergaard ${ }^{1}$, Sanne Rasmussen", Kirubakaran Balasubramaniam', Rikke Pilsgaard Svendsen', Peter Vedsted ${ }^{2}$ and Dorte Ejg Jarbøl'

\begin{abstract}
Background: Research has illustrated that the decision-making process regarding healthcare seeking for symptoms is complex and associated with a variety of factors, including gender differences. Enhanced understanding of the frequency of symptoms and the healthcare seeking behaviour in the general population may increase our knowledge of this complex field.

The primary objective of this study was to estimate the prevalence of self-reported symptoms and the proportion of individuals reporting GP contact, in a large Danish nationwide cohort. A secondary objective was to explore gender differences in GP contacts in response to experiencing one of the 44 predefined symptoms.

Methods: A Danish nationwide cohort study including a random sample of 100,000 individuals, representative of the adult Danish population aged 20 years or above. A web-based questionnaire survey formed the basis of this study. A total of 44 different symptoms covering a wide area of alarm symptoms and non-specific frequently occurring symptoms were selected based on extensive literature search. Further, items regarding contact to the GP were included. Data on socioeconomic factors were obtained from Statistics Denmark.

Results: A total of 49,706 subjects completed the questionnaire. Prevalence estimates of symptoms varied from $49.4 \%(24,537)$ reporting tiredness to $0.11 \%(54)$ reporting blood in vomit. The mean number of reported symptoms was 5.4 (men 4.8; women 6.0).

The proportion of contact to the GP with at least one symptom was $37 \%$. The largest proportion of GP contacts was seen for individuals reporting blood in the urine (73.2\%), whereas only $11.4 \%$ of individuals with increase in waist circumference reported GP contact. For almost 2/3 of the symptoms reported, no gender differences were found concerning the proportion leading to GP contacts.

Conclusion: Prevalence of symptoms and GP contacts are common in this overview of 44 different self-reported symptoms. For almost $2 / 3$ of the reported symptoms no gender differences were found concerning the proportion leading to GP contacts. An enhanced understanding of healthcare seeking decisions may assist healthcare professionals in identifying patients who are at risk of postponing contact to the GP and may help development of health campaigns targeting these individuals.
\end{abstract}

Keywords: General practice, Symptom experience, Questionnaire, Healthcare seeking, Gender, Symptom iceberg, Population based, Denmark

\footnotetext{
* Correspondence: selnegaard@health.sdu.dk

${ }^{1}$ Research Unit of General Practice, Department of Public Health, University of Southern Denmark, J.B. Winsløws Vej 9A, 5000 Odense C, Denmark Full list of author information is available at the end of the article
} 


\section{Background}

Knowledge about symptoms and healthcare seeking decisions provides an arena for understanding the interface between the healthcare system and the population. Since the 1960s we have witnessed a series of studies exploring the prevalence of symptoms and the proportion of healthcare seeking [1-5]. This phenomenon was identified as "The Symptom Iceberg" for the first time in 1963 by JM Last [1] and operationally defined by Hannay in 1979 [6]. The phenomenon depicts two parts - the "submerged part" encompassing the majority of symptom experiences, which are not brought to the attention of a general practitioner (GP), and the "surfaced part" symbolising the proportion of symptoms, which are presented to the GP.

The prevalence of self-reported symptoms varies in the existing literature. Two recent studies estimated the prevalence of symptoms, but in two different settings: a community-based survey among people with musculoskeletal complaints explored the prevalence of 25 different symptoms [7] and a population based study drawn from general practices in the UK explored the prevalence of 23 different symptoms [8]. They found an average number of symptoms experienced during the preceding 2 weeks of 3.7 and 6.0, respectively $[7,8]$. Further, research has found a wide range in the proportion who contacted the GP in response to a symptom, from 5-25\% [7-14].

Studies have illustrated that the decision process regarding healthcare seeking for a symptom is complex and depends on a variety of different factors, which possibly differ among men and women [15]. It has been argued that women are socialised to pay more attention to their bodies and tend to seek more medical advice than men [16]. However, the greater tendency to consult amongst women is not consistent in the literature $[15,17]$.

From a public health perspective people's decision about healthcare seeking is important with regard to improvements in risk profiling and diagnostics, such as e.g. cancer diagnostics. Symptoms potentially indicative of serious disease should preferably lead to healthcare seeking, while other symptoms should not. However, it is a challenge that most symptoms have low positive predictive values for serious disease [18]. Further, the awareness that some symptoms may be a sign of serious disease may differ among different groups in the population [19]. This has to be systematically explored in large-scale studies in a general population. An enhanced understanding of the size of the pool of symptoms and subsequent consequences in the population may improve policy interventions targeting healthcare seeking, e.g. systematic patient delays. Investigating a wide range of self-reported symptoms and the subsequent healthcare seeking decision is therefore important.
The primary objective of this study was to estimate the prevalence of self-reported symptoms and the proportion of individuals reporting GP contact, in a large Danish nationwide cohort. A secondary objective was to explore gender differences in GP contacts in response to experiencing one of the 44 predefined symptoms.

\section{Methods}

\section{Study design}

This study was part of a Danish nationwide cohort comprising a random sample of 100,000 individuals, representative of the adult Danish population aged 20 years or above. The overall aim of the cohort study was to estimate the prevalence of symptoms among individuals in the general population, the individuals' interpretation of symptoms, related factors influencing the decision to contact the GP and their healthcare-seeking behaviour. Further, the cohort will be followed-up using registers on health care utilization and hospital admissions to explore the predictive values of the symptoms for various diseases.

Baseline data presented in this paper were collected in a web-based survey. The data collection was conducted from June to December 2012, thereby excluding the months where the flu activity in Denmark normally peaks.

\section{Subjects and sampling}

All Danish citizens are registered with a unique personal identification number in the Danish Civil Registration System (CRS), which contains information on any Danish resident's date of birth, gender, migration, etc. The CRS enables accurate linkage between all national registers [20]. The sample for this study was randomly selected using the CRS and was invited to participate in the survey. Each individual received a postal letter explaining the purpose of the study. In the letter a unique 12-digit login for a secure webpage was included. This provided access to a comprehensive web-based questionnaire [21].

The initial invitation letter was followed by a reminder to non-respondents after two weeks. After an additional two weeks the non-respondents were contacted by telephone and encouraged to participate. In order to prevent the exclusion of people with no access to a computer, tablet or smartphone, the participants were offered the opportunity to respond to the survey in a telephone interview. Information on severe illness and subjects who had moved abroad was occasionally provided by family or relatives in the reminder procedure [21].

\section{Questionnaire}

A comprehensive questionnaire including 44 different symptoms covering a wide area of clinically relevant 
predefined symptoms was developed. For representativeness of symptoms that from a medical perspective are defined as indicating a serious disease, we selected a number of alarm symptoms of cancer covering the following areas: lung, gastrointestinal, gynaecological, and urogenital cancer. These items were selected based on a review of literature, national and international cancer referral guidelines and descriptions of cancer pathways [22-24]. In addition, we included a number of frequently occurring symptoms, which are often presented to the GP, e.g. back pain, headache and tiredness. Items regarding each specific symptom were phrased: "Have you experienced any of the following bodily sensations, symptoms or discomfort within the past four weeks?" With regard to GP contact, the question was worded for each selected symptom: "Have you contacted your general practitioner concerning the symptom(s) you have experienced within the past four weeks, through appointment, by telephone or e-mail?"

The questionnaire was pilot- and field-tested and adjusted in light of the results from these. The methodological framework for developing the questionnaire is described in details elsewhere [21].

\section{Responder analysis}

In order to compare the study sample, respondents and non-respondents, data on socioeconomic and demographic factors were collected from Statistics Denmark [25]. For each individual we obtained information on education, income, labour market affiliation, cohabitation status, ethnicity and average number of contacts to the GP. Information was retrieved for the year 2011, i.e. the year preceding the questionnaire study. Education was categorised according to the length of the highest attained educational level: low ( $<10$ years (primary and lower secondary school)); middle (10-12 years (vocational education and upper secondary school)); and high (>12 years (short-, medium- and long-term higher education)). This categorisation was selected to reflect the organisation of the Danish educational system [26]. Equivalence weighted disposable income was categorised as low income (1st quartile), middle income (2nd and 3rd quartile), and high income (4th quartile). Labour market affiliation was categorised into three groups: (i) working, (ii) pensioners and (iii) out of the workforce. Cohabitation status was categorised into: cohabiting/married or single. Ethnicity was categorised into three groups: persons with Danish origin, immigrants, and descendants of immigrants. The total number of contacts to the GP in 2011 was obtained from the National Health Service Register [25].

\section{Statistical analysis}

The following socioeconomic and demographic characteristics of the study sample, respondents and non- respondents were described: sex, age, education, income, labour market affiliation, cohabitation status, ethnicity and average contacts to GP the preceding year. Chi-square tests were used to test for differences between characteristics of respondents and non-respondents.

Prevalence estimates of each reported symptom and the proportion of individuals with contact to the GP were calculated with $95 \%$ confidence intervals based on the binominal distribution. The reported symptoms were ranked according to their frequency. Respondents answering "not relevant for me" were excluded from the analysis and the answers "do not wish to answer" which accounted for less than $5 \%$, was considered as missing and not included in the analyses. In order to explore the pattern of "The Symptom Iceberg" for each gender, the prevalence of symptom experiences and proportion of contacts to the GP were stratified on gender. We tested whether the prevalence estimates differed between genders using chi-squared tests. Contacts to GP were ranked separately for men and women, according to the proportion contacting the GP in response to experiencing a symptom.

A histogram of the number of reported symptoms by the participants was constructed for the full sample as well as for men and women separately. For each number of symptoms, the proportion contacting the GP with at least one of the symptoms was indicated. All data analyses were conducted using StataIC 13๑.

\section{Ethical approval}

The Regional Scientific Ethics Committee for Southern Denmark evaluated the project and concluded that no further approval was necessary due to Danish legislation. The participants in the study were clearly informed that there would be no clinical follow-up, and that they should contact their own GP in case of concern or worry. The project was approved by the Danish Data Protection Agency (journal no. 2011-41-6651).

\section{Results and discussion}

Of the 100,000 randomly selected subjects, 4,474 (4.7\%) were not eligible because they had either died, were suffering from severe illnesses (including dementia), had language problems, had moved abroad or could not be reached due to unknown address. Of the 95,253 (95.3\%) eligible subjects, 49,706 subjects completed the questionnaire, yielding a response rate of $52.2 \%$. Some 1,208 $(2.4 \%)$ completed the questionnaire by telephone. Of all non-respondents, 26,008 (57.1\%) indicated that they did not wish to participate in the study, whereas for the remaining 19,539 (42.9\%) no contact was achieved during the reminder procedure (Fig. 1). The electronic format of the questionnaire enabled a leap structure, so the respondents were directed through the questionnaire 


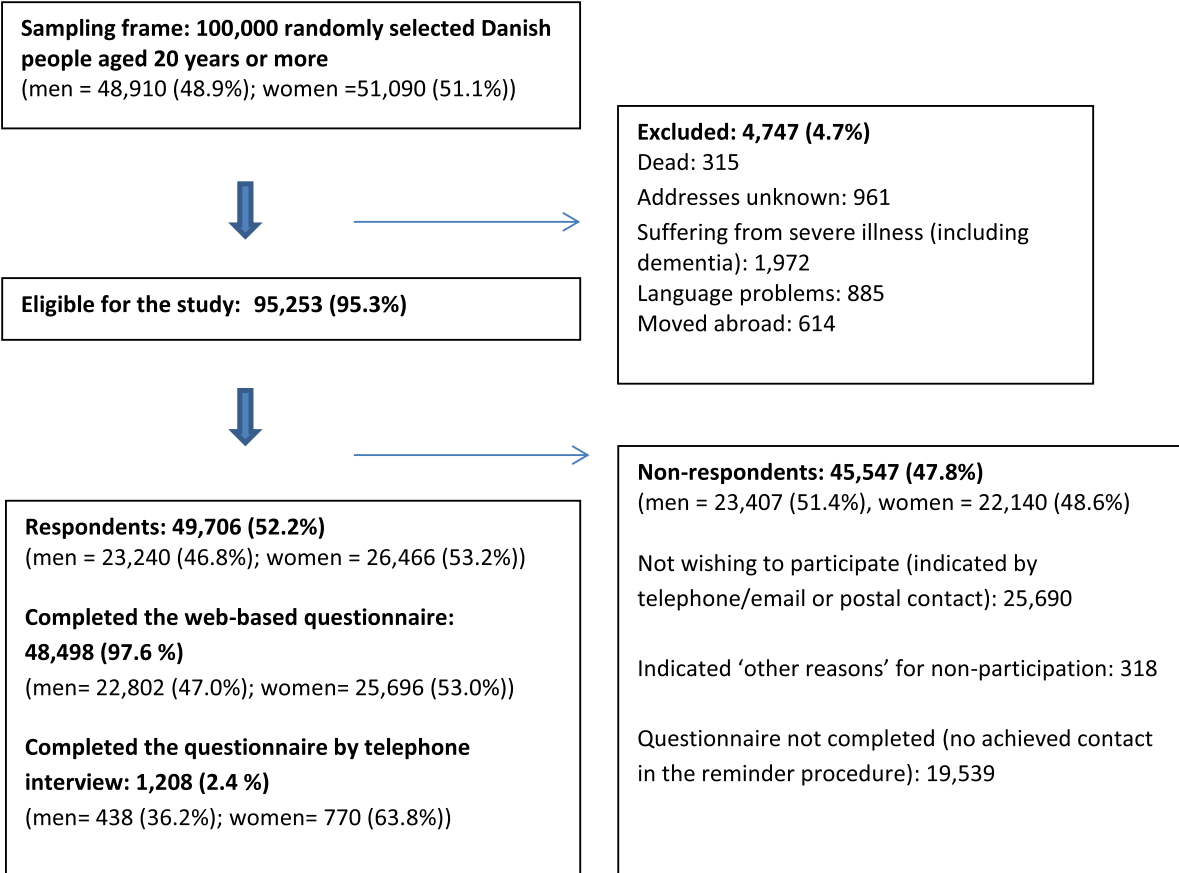

Fig. 1 Study cohort

according to their previously given answers, skipping irrelevant questions. Further, the structure ensured that respondents were required to answer each question in order to continue to the next. Less than $5 \%$ of the respondents did not complete the questionnaire.

Table 1 shows socioeconomic and demographic characteristics of the total study sample, respondents and non-respondents, respectively. The median age of the study sample was 51 years (IQR 38-65). Median age of respondents was slightly higher than nonrespondents; 52 years (IQR 40-64) compared to 50 years (IQR 36-66), respectively. The respondents were fairly representative of the study sample. However, more respondents were females, married/living together, had a high educational and income level and were attached to the labour market. Differences between respondents, non-respondents and the study sample according to descriptive characteristics are shown in Table 1.

Prevalence estimates of self-reported symptoms in the preceding four weeks and the proportions of individuals with report of contact to the GP are listed in Table 2. Prevalence estimates of symptoms varied from $49.4 \%$ $(24,537)$ reporting tiredness to $0.11 \%(54)$ reporting blood in vomit. The symptoms are ranked by frequency. The largest proportion of GP contacts was observed for individuals reporting blood in the urine $73.2 \%$, whereas $11.4 \%$ of individuals with increase in waist circumference reported contact to the GP (Table 2).
About 9 out of 10 respondents reported at least one symptom within the preceding four weeks. The mean number of reported symptoms was 5.4 (men: 4.8; women: 6.0, $\mathrm{p}<0.001$ ). The number of symptoms reported ranged from 0 to 39 . Figure 2, illustrates the proportion who reported the given number of symptoms and the proportion with the given number of symptoms who contacted the GP with at least one symptom. Women were most likely to have reported four symptoms within the preceding four weeks, while men were most likely to have reported two symptoms. The proportion of symptoms leading to GP contacts increased with increasing number of symptoms experienced. This was similar for both men and women (Fig. 2). The genderspecific prevalences of reported symptoms and proportions of GP contact are listed in Table 3.

In total, $37 \%$ contacted the GP with at least one symptom. For almost $2 / 3$ of the reported symptoms, no statistically significant differences in reporting contacts to GP were found between the genders. However, women more often than men contacted the GP with repeated vomiting, coughing, tiredness and lack of energy, whereas men more often than women contacted the GP with stress incontinence, difficulties emptying the bladder, frequent urination, night-time urination and swollen legs (Table 3).

\section{Summary of main findings}

This population based nationwide study demonstrated that symptoms were common; about 9 out of 10 individuals 
Table 1 Descriptive characteristics of the total sample, respondents and non-respondents in the survey $(N=100000)$

\begin{tabular}{|c|c|c|c|c|c|c|c|}
\hline & Total sample & Respondents & Non-respondents & & & & \\
\hline & $\bar{N}$ & $\%$ & $n$ & $\%$ & $\mathrm{n}$ & $\%$ & P-value* \\
\hline \multicolumn{8}{|l|}{ Sex } \\
\hline Male & 48910 & 48.9 & 23240 & 46.8 & 23407 & 51.4 & \multirow[t]{2}{*}{$<0.001$} \\
\hline Female & 51090 & 51.1 & 26466 & 53.2 & 22140 & 48.6 & \\
\hline \multicolumn{8}{|l|}{ Age } \\
\hline $20-39$ & 27706 & 27.7 & 12251 & 24.6 & 15455 & 30.7 & \multirow[t]{4}{*}{$<0.001$} \\
\hline $40-59$ & 37106 & 37.1 & 20305 & 40.9 & 16801 & 33.4 & \\
\hline $60-79$ & 28868 & 28.9 & 15748 & 31.7 & 13120 & 26.1 & \\
\hline $80-$ & 6320 & 6.3 & 1402 & 2.8 & 4918 & 9.8 & \\
\hline \multicolumn{8}{|l|}{ Marital status ${ }^{\mathrm{a}}$} \\
\hline Single & 31140 & 32.8 & 12475 & 25.1 & 18665 & 41.2 & \multirow[t]{2}{*}{$<0.001$} \\
\hline Married/living together & 63807 & 67.2 & 37140 & 74.9 & 26667 & 58.8 & \\
\hline \multicolumn{8}{|l|}{ Educational level $^{a}$} \\
\hline Low & 24770 & 27.2 & 9540 & 19.7 & 15230 & 35.6 & \multirow[t]{3}{*}{$<0.001$} \\
\hline Medium & 40659 & 44.6 & 22155 & 45.8 & 18504 & 43.3 & \\
\hline High & 25752 & 28.2 & 16724 & 34.5 & 9028 & 21.1 & \\
\hline \multicolumn{8}{|l|}{ Income level $^{\mathrm{a}}$} \\
\hline Low & 22440 & 23.6 & 8072 & 16.3 & 14368 & 31.7 & \multirow[t]{3}{*}{$<0.001$} \\
\hline Medium & 48126 & 50.7 & 25712 & 41.8 & 22414 & 49.4 & \\
\hline High & 24382 & 25.7 & 24382 & 31.9 & 8551 & 18.9 & \\
\hline \multicolumn{8}{|l|}{ Employment status ${ }^{a}$} \\
\hline Workning & 59961 & 63.1 & 33961 & 68.4 & 26000 & 57.3 & \multirow[t]{3}{*}{$<0.001$} \\
\hline Pensioners & 23193 & 24.4 & 11294 & 22.7 & 11899 & 26.2 & \\
\hline Out of workforce & 11911 & 12.5 & 4410 & 8.9 & 7501 & 16.5 & \\
\hline \multicolumn{8}{|l|}{ Ethnic groups ${ }^{a}$} \\
\hline Danish & 86248 & 90.8 & 46543 & 93.8 & 39705 & 87.6 & \multirow[t]{3}{*}{$<0.001$} \\
\hline Immigrants & 8038 & 8.5 & 2858 & 5.8 & 5180 & 11.4 & \\
\hline Descendants of Immigrants & 661 & 0.7 & 214 & 0.4 & 447 & 1.0 & \\
\hline \multicolumn{8}{|l|}{ GP contacts $^{\mathrm{a}}$} \\
\hline Average contacts to GP in 2011 & 8.1 & & 7.6 & & 8.5 & & $<0.001$ \\
\hline
\end{tabular}

Total numbers for each group may not add up to full sample, 5 to $9 \%$ missing data from Statistics Denmark

*Differences between respondents and non-respondents according to descriptive characteristics were tested using chi-square tests

reported at least one symptom within the preceding four weeks. On average, women reported more symptoms than men; however, for some symptom the prevalence was higher for men. The majority of reported symptoms were not presented to the GP; the proportion of respondents contacting the GP with at least one symptom was $37 \%$. For $2 / 3$ of the reported symptoms no gender differences in GP contacts were found.

\section{Strengths and limitations of the study}

This study is a large nationwide population based study, including 100,000 individuals randomly selected from the Danish CRS register, representative of the adult Danish population aged 20 or above. To our knowledge such a large-scale population based study, investigating a wide range of self-reported symptoms covering specific and nonspecific cancer alarm symptoms as well as frequently occurring symptoms, has not previously been conducted.

The response rate of $52.2 \%$ was comparable or even higher compared to previous surveys measuring symptom prevalences in the general population [27]. However, it is unknown whether individuals who had experienced symptoms might have been less or more inclined to participate in the study. 
Table 2 The Symptom Iceberg - Prevalence of self-reported symptoms in the previous 4 weeks and the proportion of GP contacts. Ranked from 1 to 44 according to proportion of symptoms in the study population

\begin{tabular}{|c|c|c|c|c|c|c|c|}
\hline & \multicolumn{4}{|c|}{ Proportion with symptoms } & \multicolumn{3}{|c|}{ Proportion with GP contacts } \\
\hline & $\bar{N}$ & $\%$ & {$[95 \% \mathrm{Cl}]$} & Rank & $\mathrm{N}$ & $\%$ & {$[95 \% \mathrm{Cl}]$} \\
\hline Tiredness & 24537 & 49.8 & {$[49.4-50.3]$} & 1 & 4907 & 20.2 & [19.7-20.7] \\
\hline Night-time urination & 23935 & 48.7 & {$[48.2-49.1]$} & 2 & 3024 & 12.8 & {$[12.3-13.2]$} \\
\hline Lack of energy & 18472 & 37.5 & {$[37.1-37.9]$} & 3 & 3599 & 19.7 & [19.1-20.3] \\
\hline Headache & 17978 & 36.5 & {$[36.1-37.0]$} & 4 & 3159 & 17.7 & {$[17.2-18.3]$} \\
\hline Back pain & 15925 & 32.3 & {$[31.9-32.8]$} & 5 & 5490 & 34.9 & {$[34.1-35.6]$} \\
\hline Abdominal bloating & 14712 & 29.8 & {$[29.4-30.2]$} & 6 & 1864 & 12.9 & {$[12.3-13.4]$} \\
\hline Memory problems & 9824 & 19.9 & {$[19.6-20.3]$} & 7 & 1771 & 18.3 & [17.6-19.1] \\
\hline Abdominal pain & 9765 & 19.6 & {$[19.4-20.1]$} & 8 & 2659 & 27.8 & [26.9-28.7] \\
\hline Erectile dysfunction $^{a}$ & 4289 & 19.3 & [18.8-19.8] & 9 & 1362 & 32.1 & {$[30.7-33.5]$} \\
\hline Coughing & 8804 & 17.9 & {$[17.5-18.2]$} & 10 & 2120 & 24.4 & {$[23.5-25.3]$} \\
\hline Concentration problems & 8662 & 17.6 & {$[17.2-17.9]$} & 11 & 1742 & 20.4 & {$[19.6-21.3]$} \\
\hline Change in stool texture & 8543 & 17.3 & {$[17.0-17.6]$} & 12 & 1260 & 15.0 & [14.3-15.8] \\
\hline Dizziness & 7889 & 16.0 & {$[15-7-16-3]$} & 13 & 2407 & 30.9 & [29.9-32.0] \\
\hline Pelvic pain ${ }^{a}$ & 3963 & 15.4 & {$[14.9-15.8]$} & 14 & 1008 & 25.8 & {$[24.4-27.2]$} \\
\hline Feeling unwell & 7411 & 15.0 & {$[14.7-15.4]$} & 15 & 2065 & 28.3 & {$[27.3-29.3]$} \\
\hline Constipation & 7231 & 14.7 & {$[14.3-15.0]$} & 16 & 970 & 13.6 & {$[12.9-14.5]$} \\
\hline Increase in waist circumference & 6548 & 13.3 & {$[13.0-13.7]$} & 17 & 733 & 11.4 & {$[10.6-12.2]$} \\
\hline Change in stool frequency & 6466 & 13.1 & {$[12.8-13.4]$} & 18 & 1009 & 15.9 & {$[15.0-16.8]$} \\
\hline Diarrhoea & 6385 & 12.9 & {$[12.7-13.2]$} & 19 & 1057 & 16.8 & {$[15.9-17.7]$} \\
\hline Nausea & 6256 & 12.6 & {$[12.3-12.9]$} & 20 & 1264 & 20.6 & [19.6-21.6] \\
\hline Swollen legs & 6056 & 12.3 & {$[12.0-12.6]$} & 21 & 2224 & 37.2 & {$[36.0-38.5]$} \\
\hline Difficulty in emptying the bladder & 5731 & 11.6 & {$[11.4-11.9]$} & 22 & 1534 & 27.1 & [26.0-28.3] \\
\hline Frequent urination & 5234 & 10.6 & [10.4-10.9] & 23 & 1362 & 26.5 & {$[25.3-27.7]$} \\
\hline Pelvic pain during intercourse ${ }^{a}$ & 2091 & 10.2 & {$[9.8-10.6]$} & 24 & 552 & 26.6 & [24.8-28.6] \\
\hline Stress incontinence & 4797 & 9.8 & {$[9.5-10.0]$} & 25 & 852 & 18.0 & [16.8-19.1] \\
\hline Shortness of breath & 3960 & 8.0 & {$[7.8-8.3]$} & 26 & 1936 & 49.7 & {$[48.1-51.2]$} \\
\hline Hoarseness & 3782 & 7.7 & {$[7.4-7.9]$} & 27 & 698 & 18.7 & {$[17.5-20.0]$} \\
\hline Urge incontinence & 3080 & 6.3 & {$[6.0-6.5]$} & 28 & 790 & 26.1 & {$[24.5-27.6]$} \\
\hline Loss of appetite & 3079 & 6.3 & {$[6.0-6.5]$} & 29 & 586 & 19.4 & [18.1-20.9] \\
\hline Blood in stool/rectal bleeding & 2285 & 4.6 & {$[4.4-4.8]$} & 30 & 758 & 33.7 & {$[31.8-35.7]$} \\
\hline Fever & 1952 & 4.0 & {$[3.8-4.1]$} & 31 & 517 & 26.8 & {$[24.9-28.8]$} \\
\hline Difficulty swallowing & 1727 & 3.5 & {$[3.3-3.7]$} & 32 & 586 & 34.9 & {$[32.6-37.2]$} \\
\hline Weight loss & 1490 & 3.0 & {$[2.9-3.2]$} & 33 & 363 & 25.1 & {$[23.0-27.4]$} \\
\hline Vaginal bleeding after intercourse ${ }^{a}$ & 612 & 3.0 & {$[2.8-3.2]$} & 34 & 187 & 30.9 & {$[27.2-34.7]$} \\
\hline Incontinence without stress/urge & 1158 & 2.3 & {$[2.2-2.5]$} & 35 & 383 & 33.8 & {$[31.1-36.6]$} \\
\hline Postmenopausal bleeding ${ }^{a}$ & 370 & 2.3 & {$[2.1-2.5]$} & 36 & 118 & 33.1 & {$[28.2-38.2]$} \\
\hline Pain/burning when urinating & 1046 & 2.1 & {$[2.0-2.3]$} & 37 & 489 & 47.8 & {$[44.7-50.8]$} \\
\hline Lump/swollen lymph nodes & 811 & 1.6 & {$[1.5-1.8]$} & 38 & 332 & 41.5 & {$[38.1-45.0]$} \\
\hline Black stool & 779 & 1.6 & {$[1.5-1.7]$} & 39 & 132 & 17.3 & {$[14.8-20.2]$} \\
\hline Repeated vomiting & 643 & 1.3 & {$[1.2-1.4]$} & 40 & 208 & 33.6 & {$[30.0-37.4]$} \\
\hline Blood in urine & 284 & 0.6 & {$[0.5-0.7]$} & 41 & 202 & 73.2 & [67.6-78.1] \\
\hline Blood in semen ${ }^{a}$ & 94 & 0.4 & {$[0.3-0.5]$} & 42 & 45 & 48.9 & [38.7-59.2] \\
\hline
\end{tabular}


Table 2 The Symptom Iceberg - Prevalence of self-reported symptoms in the previous 4 weeks and the proportion of GP contacts. Ranked from 1 to 44 according to proportion of symptoms in the study population (Continued)

\begin{tabular}{llllllll}
\hline Coughing up blood & 62 & 0.1 & {$[0.1-0.2]$} & 43 & 29 & 47.5 & {$[35.1-60.3]$} \\
Blood in vomit & 54 & 0.1 & {$[0.1-0.1]$} & 44 & 17 & 37.0 & {$[23.9-52.2]$} \\
\hline
\end{tabular}

${ }^{\mathrm{a} G e n d e r ~ s p e c i f i c ~ s y m p t o m s ~}$

Information on symptoms and healthcare seeking decisions was self-reported, and respondents were asked to recall which of the 44 symptoms they had experienced in the preceding four weeks, and whether they at any time had contacted the GP with the symptoms they had experienced within the past four weeks. However, recall bias cannot be ruled out in questionnaire studies [28]. Some may misplace previous experiences of symptoms into the specified timeframe due to the severity of the symptoms or because they had contacted the GP about them [29]. Others may have forgotten about the experience of symptoms or GP contact because the symptom turned out to be inconsequential, or simply due to memory decay [30]. A higher proportion of individuals reporting GP contact with a symptom was found compared to other studies which might be explained by the unspecified timeframe for GP contact. In particular, this may be the case for the more frequently occurring symptoms such as back pain.

The web-based questionnaire was not available in a paper version, which might have prevented some individuals from participating in the study, especially the elderly. However, this possible selection bias was sought minimised by offering individuals without a computer the possibility to complete the survey by telephone interview.

\section{Symptoms and measurement - The Symptom Iceberg}

When measuring symptoms, it is essential to define what a symptom is and how to measure it. As stated by Kroenke 'symptoms research is a fertile field' [31], and we need to be more explicit about the way we conceptualise and measure symptoms. In this study we consider symptoms to be subjective interpretations of sensations and bodily changes, which are not necessarily an indication of an underlying disease.

Since no gold standard for measuring symptoms exits, studies on the prevalence of reported symptoms use different methodological approaches, which complicate comparison of the results between studies. However, despite the methodological differences, our results regarding the most frequently experienced symptoms are broadly consistent with previous symptom research $[6,8,32]$. This study focuses on individual reported symptoms, the total number of reported symptoms and corresponding contacts to the GP. Future studies might address how specific clusters of symptoms may affect the proportion of GP contacts.

\section{Gender differences}

Some studies on symptoms and GP contacts suggest that men are less likely than women to report symptoms and

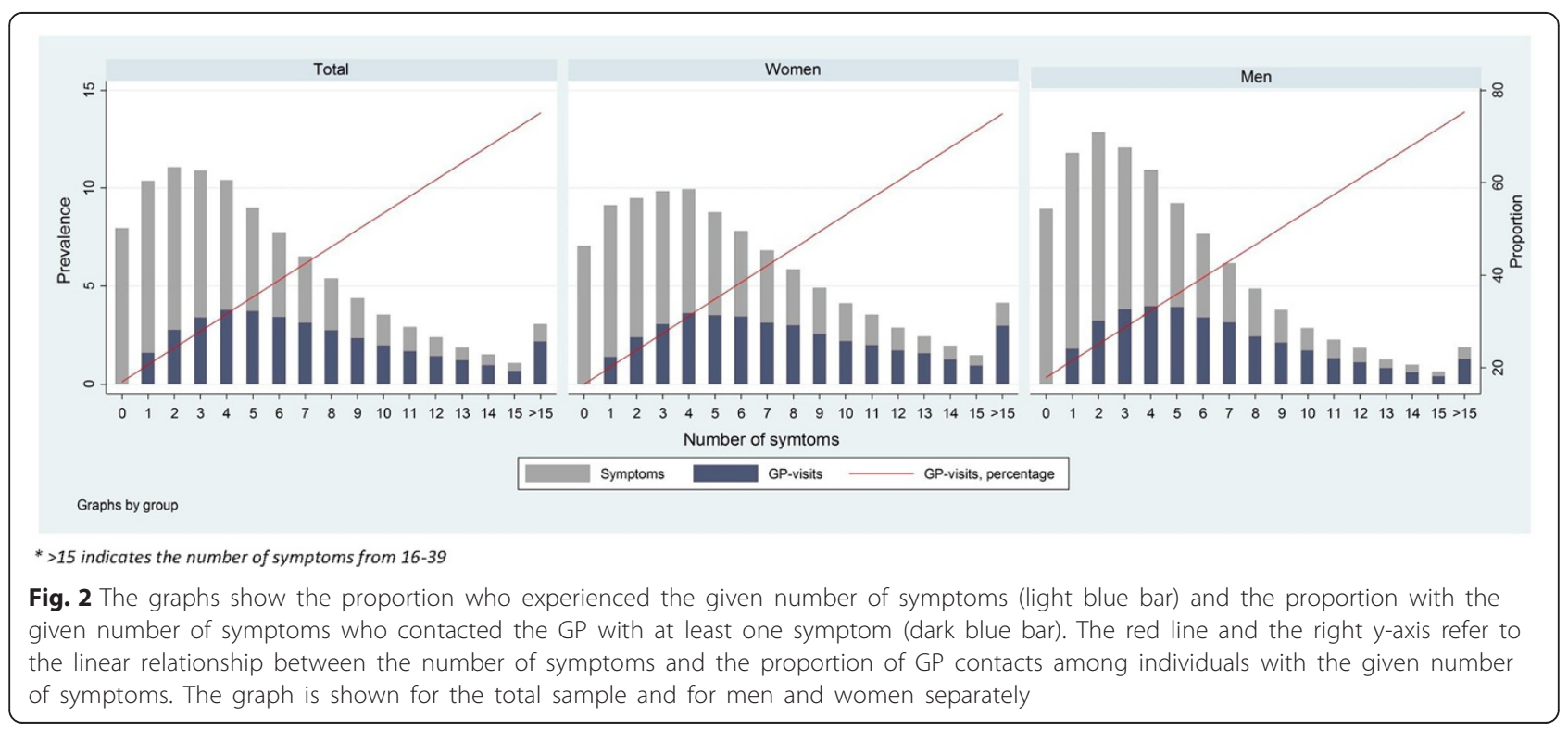


Table 3 Prevalence of symptoms and GP contacts, stratified on gender. Proportions of GP-contacts were ranked from 1 to 42 according to frequency

\begin{tabular}{|c|c|c|c|c|c|c|c|c|}
\hline & \multicolumn{3}{|c|}{ Proportion with symptoms } & \multicolumn{5}{|c|}{ Proportion with GP contacts } \\
\hline & Gender & $n$ & $\%$ & $n$ & $\%$ & {$[95 \% \mathrm{Cl}]$} & Rank & $p$-value \\
\hline \multirow[t]{2}{*}{ Tiredness } & Men & 10642 & 45.8 & 1923 & 18.3 & {$[17.5-19.0]$} & 28 & $<0.001$ \\
\hline & Women & 13895 & 52.5 & 2984 & 21.7 & {$[21.0-22.4]$} & 26 & \\
\hline \multirow[t]{2}{*}{ Night-time urination } & Men & 11424 & 49.2 & 1928 & 17.0 & {$[16.3-17.7]$} & 31 & $<0.001$ \\
\hline & Women & 12511 & 47.3 & 1096 & 8.9 & {$[8.4-9.4]$} & 42 & \\
\hline \multirow[t]{2}{*}{ Lack of energy } & Men & 8215 & 35.3 & 1437 & 17.7 & {$[16.8-18.5]$} & 29 & $<0.001$ \\
\hline & Women & 10257 & 38.8 & 2162 & 21.4 & {$[20.6-22.2]$} & 27 & \\
\hline \multirow[t]{2}{*}{ Headache } & Men & 6675 & 28.7 & 1016 & 15.3 & {$[14.5-16.2]$} & 36 & $<0.001$ \\
\hline & Women & 11303 & 42.7 & 2143 & 19.2 & [18.4-19.9] & 34 & \\
\hline \multirow[t]{2}{*}{ Back pain } & Men & 7067 & 30.4 & 2468 & 35.2 & {$[34.1-36.3]$} & 10 & 0.437 \\
\hline & Women & 8858 & 33.5 & 3022 & 34.6 & {$[33.6-35.6]$} & 8 & \\
\hline \multirow[t]{2}{*}{ Abdominal bloating } & Men & 5073 & 21.8 & 674 & 13.5 & {$[21.5-14.5]$} & 38 & 0.101 \\
\hline & Women & 9639 & 36.4 & 1190 & 12.5 & [11.9-13.2] & 40 & \\
\hline \multirow[t]{2}{*}{ Memory problems } & Men & 4177 & 18.0 & 691 & 16.8 & [15.7-18.0] & 32 & 0.001 \\
\hline & Women & 5647 & 21.3 & 1080 & 19.5 & [18.4-20.5] & 33 & \\
\hline \multirow[t]{2}{*}{ Abdominal pain } & Men & 3273 & 14.1 & 1002 & 31.3 & {$[29.7-32.9]$} & 16 & $<0.001$ \\
\hline & Women & 6492 & 24.5 & 1657 & 26.0 & {$[25.0-27.2]$} & 19 & \\
\hline \multirow[t]{2}{*}{ Coughing } & Men & 4212 & 18.1 & 953 & 22.9 & {$[21.6-24.2]$} & 24 & 0.002 \\
\hline & Women & 4592 & 17.4 & 1167 & 25.7 & {$[24.5-27.0]$} & 21 & \\
\hline \multirow[t]{2}{*}{ Concentration problems } & Men & 3566 & 15.3 & 687 & 19.5 & {$[18.2-20.9]$} & 26 & 0.089 \\
\hline & Women & 5096 & 19.3 & 1055 & 21.0 & [19.9-22.2] & 28 & \\
\hline \multirow[t]{2}{*}{ Change in stool texture } & Men & 3858 & 16.6 & 542 & 14.3 & {$[13.2-15.4]$} & 37 & 0.083 \\
\hline & Women & 4685 & 17.7 & 718 & 15.6 & {$[14.6-16.7]$} & 37 & \\
\hline \multirow[t]{2}{*}{ Dizziness } & Men & 3101 & 13.3 & 961 & 31.3 & {$[29.7-33.0]$} & 15 & 0.557 \\
\hline & Women & 4788 & 18.1 & 1446 & 30.7 & {$[29.4-32.0]$} & 14 & \\
\hline \multirow[t]{2}{*}{ Feeling unwell } & Men & 3042 & 13.1 & 831 & 27.7 & {$[26.1-29.3]$} & 19 & 0.337 \\
\hline & Women & 4369 & 16.5 & 1234 & 28.7 & {$[27.4-30.1]$} & 15 & \\
\hline \multirow[t]{2}{*}{ Constipation } & Men & 2422 & 10.4 & 317 & 13.3 & {$[12.0-14.7]$} & 39 & 0.542 \\
\hline & Women & 4809 & 18.2 & 653 & 13.8 & {$[12.9-14.8]$} & 39 & \\
\hline \multirow[t]{2}{*}{ Increase in waist circumference } & Men & 2266 & 9.7 & 217 & 9.7 & {$[8.5-11.0]$} & 40 & 0.002 \\
\hline & Women & 4282 & 16.2 & 516 & 12.3 & {$[11.3-13.3]$} & 41 & \\
\hline \multirow[t]{2}{*}{ Change in stool frequency } & Men & 2757 & 11.9 & 444 & 16.5 & {$[15.1-17.9]$} & 33 & 0.308 \\
\hline & Women & 3709 & 14.0 & 565 & 15.5 & {$[14.4-16.7]$} & 38 & \\
\hline \multirow[t]{2}{*}{ Diarrhoea } & Men & 2946 & 12.7 & 476 & 16.4 & {$[15.1-17.8]$} & 34 & 0.436 \\
\hline & Women & 3439 & 13.0 & 581 & 17.1 & {$[15.9-18.5]$} & 35 & \\
\hline \multirow[t]{2}{*}{ Nausea } & Men & 1887 & 8.1 & 391 & 21.1 & {$[19.2-23.0]$} & 25 & 0.522 \\
\hline & Women & 4369 & 16.5 & 873 & 20.4 & {$[19.2-21.6]$} & 29 & \\
\hline \multirow[t]{2}{*}{ Swollen legs } & Men & 1953 & 8.4 & 870 & 45.1 & {$[42.8-47.3]$} & 4 & $<0.001$ \\
\hline & Women & 4103 & 15.5 & 1354 & 33.5 & {$[32.1-35.0]$} & 10 & \\
\hline \multirow[t]{2}{*}{ Difficulty in emptying the bladder } & Men & 3365 & 14.5 & 995 & 29.9 & {$[28.4-31.5]$} & 17 & $<0.001$ \\
\hline & Women & 2366 & 8.9 & 539 & 23.1 & {$[21.4-24-9]$} & 25 & \\
\hline \multirow[t]{2}{*}{ Frequent urination } & Men & 2597 & 11.2 & 738 & 28.8 & {$[27.0-30.6]$} & 18 & $<0.001$ \\
\hline & Women & 2637 & 10.0 & 624 & 24.2 & {$[22.5-25.9]$} & 24 & \\
\hline
\end{tabular}


Table 3 Prevalence of symptoms and GP contacts, stratified on gender. Proportions of GP-contacts were ranked from 1 to 42 according to frequency (Continued)

\begin{tabular}{|c|c|c|c|c|c|c|c|c|}
\hline \multirow[t]{2}{*}{ Stress incontinence } & Men & 256 & 1.1 & 90 & 35.7 & {$[29.8-42.0]$} & 9 & $<0.001$ \\
\hline & Women & 4541 & 17.2 & 762 & 17.0 & [15.9-18.1] & 36 & \\
\hline \multirow[t]{2}{*}{ Erectile dysfunction ${ }^{a}$} & Men & 4289 & 18.5 & 1362 & 32.1 & {$[30.7-33.5]$} & 14 & - \\
\hline & - & - & - & - & - & - & - & \\
\hline \multirow[t]{2}{*}{ Pelvic pain ${ }^{a}$} & - & - & - & - & - & - & - & - \\
\hline & Women & 3963 & 15.0 & 1008 & 25.8 & {$[24.4-27.2]$} & 20 & \\
\hline \multirow[t]{2}{*}{ Shortness of breath } & Men & 1912 & 8.3 & 960 & 50.9 & {$[48.6-53.2]$} & 2 & 0.139 \\
\hline & Women & 2048 & 7.7 & 976 & 48.5 & {$[46.3-50.7]$} & 4 & \\
\hline \multirow[t]{2}{*}{ Hoarseness } & Men & 1677 & 7.2 & 293 & 17.7 & [15.9-19.6] & 30 & 0.147 \\
\hline & Women & 2105 & 8.0 & 405 & 19.6 & [17.9-21.3] & 32 & \\
\hline \multirow[t]{2}{*}{ Urge incontinence } & Men & 1184 & 5.1 & 322 & 27.7 & {$[25.2-30.4]$} & 20 & 0.102 \\
\hline & Women & 1896 & 7.2 & 468 & 25.0 & {$[23.1-27.1]$} & 23 & \\
\hline \multirow[t]{2}{*}{ Loss of appetite } & Men & 1359 & 5.8 & 256 & 19.2 & {$[17.1-21.4]$} & 27 & 0.767 \\
\hline & Women & 1720 & 6.5 & 330 & 19.6 & {$[17.7-21.6]$} & 31 & \\
\hline \multirow[t]{2}{*}{ Blood in stool/rectal bleeding } & Men & 1103 & 4.7 & 366 & 33.7 & {$[30.9-36.6]$} & 12 & 0.963 \\
\hline & Women & 1182 & 4.5 & 392 & 33.8 & {$[31.1-36.6]$} & 9 & \\
\hline \multirow[t]{2}{*}{ Pelvic pain during intercourse ${ }^{a}$} & - & - & - & - & - & - & - & - \\
\hline & Women & 2091 & 7.9 & 552 & 26.6 & {$[24.7-28.6]$} & 18 & \\
\hline \multirow[t]{2}{*}{ Fever } & Men & 841 & 3.6 & 211 & 25.3 & {$[22.4-28.4]$} & 22 & 0.18 \\
\hline & Women & 1111 & 4.2 & 306 & 28.0 & {$[25.4-30.8]$} & 16 & \\
\hline \multirow[t]{2}{*}{ Difficulty swallowing } & Men & 781 & 3.4 & 254 & 33.2 & {$[29.9-36.7]$} & 13 & 0.205 \\
\hline & Women & 946 & 3.6 & 332 & 36.2 & {$[33.1-39.4]$} & 7 & \\
\hline \multirow[t]{2}{*}{ Weight loss } & Men & 768 & 3.3 & 185 & 24.8 & {$[21.7-28.1]$} & 23 & 0.758 \\
\hline & Women & 722 & 2.7 & 178 & 25.5 & {$[22.3-28.9]$} & 22 & \\
\hline \multirow[t]{2}{*}{ Incontinence without stress/urge } & Men & 328 & 1.4 & 111 & 34.7 & {$[29.5-40.2]$} & 11 & 0.703 \\
\hline & Women & 830 & 3.1 & 272 & 33.5 & {$[30.3-36.9]$} & 11 & \\
\hline \multirow[t]{2}{*}{ Pain/burning when urinating } & Men & 384 & 1.5 & 156 & 41.4 & {$[36.4-46.5]$} & 6 & 0.002 \\
\hline & Women & 662 & 2.5 & 333 & 51.5 & {$[47.5-55.4]$} & 3 & \\
\hline \multirow[t]{2}{*}{ Lump/swollen lymph nodes } & Men & 268 & 1.2 & 109 & 40.8 & {$[34.9-47.0]$} & 7 & 0.784 \\
\hline & Women & 543 & 2.1 & 223 & 41.8 & {$[37.6-46.2]$} & 5 & \\
\hline \multirow[t]{2}{*}{ Black stool } & Men & 451 & 1.9 & 68 & 15.4 & {$[12.1-19.1]$} & 35 & 0.093 \\
\hline & Women & 328 & 1.2 & 64 & 20.1 & {$[15.8-24.9]$} & 30 & \\
\hline \multirow[t]{2}{*}{ Repeated vomiting } & Men & 243 & 1.0 & 62 & 26.8 & {$[21.2-33.0]$} & 21 & 0.006 \\
\hline & Women & 400 & 1.5 & 146 & 37.6 & {$[32.8-42.7]$} & 6 & \\
\hline \multirow[t]{2}{*}{ Vaginal bleeding after intercourse ${ }^{a}$} & - & - & - & - & - & - & - & - \\
\hline & Women & 612 & 2.3 & 187 & 30.9 & {$[27.2-34.7]$} & 13 & \\
\hline \multirow[t]{2}{*}{ Postmenopausal bleeding ${ }^{a}$} & - & - & - & - & - & - & - & - \\
\hline & Women & 370 & 1.4 & 118 & 33.1 & {$[28.2-38.2]$} & 12 & \\
\hline \multirow[t]{2}{*}{ Blood in urine } & Men & 125 & 0.5 & 86 & 69.9 & {$[61.0-77.9]$} & 1 & 0.272 \\
\hline & Women & 159 & 0.6 & 116 & 75.8 & {$[68.2-82.4]$} & 1 & \\
\hline \multirow[t]{2}{*}{ Blood in semen ${ }^{a}$} & Men & 94 & 0.4 & 45 & 48.9 & {$[38.3-59.6]$} & 3 & - \\
\hline & - & - & - & - & - & - & - & \\
\hline \multirow[t]{2}{*}{ Coughing up blood } & Men & 42 & 0.2 & 18 & 43.9 & {$[28.5-60.3]$} & 5 & 0.415 \\
\hline & Women & 20 & 0.1 & 11 & 55.0 & [31.5-76.9] & 2 & \\
\hline
\end{tabular}


Table 3 Prevalence of symptoms and GP contacts, stratified on gender. Proportions of GP-contacts were ranked from 1 to 42 according to frequency (Continued)

\begin{tabular}{llllllll}
\hline Blood in vomit & Men & 32 & 0.1 & 11 & 39.3 & {$[21.5-59.4]$} & 8 \\
& Women & 22 & 0.1 & 6 & 33.3 & {$[13.3-59.0]$} & 17 \\
\hline
\end{tabular}

*Differences in GP-contacts with a symptom between genders were tested using chi-square tests

${ }^{a}$ Total numbers for each gender specific symptoms may not add up to full sample, due to the answer "do not wish to answer" was considered as missing (1.1-4.6\%) in the analyses

to contact the GP [33]. However, other studies suggest that once a symptom is experienced and recognised, there are no gender differences in the tendency to contact the GP [5, 34, 35]. The results of this study show that for almost $2 / 3$ of the reported symptoms, no statistically significant gender differences in reporting contact to GP were found.

\section{GP contacts - The "surfaced" part of The Symptom Iceberg}

We found that $37 \%$ contacted the GP with at least one of the symptoms experienced within the preceding four weeks. This proportion is relatively high compared to existing literature [5, 11-13, 27]. The original concept about "The Symptom Iceberg" was that approximately $10 \%$ of all symptoms resulted in contact to the GP [36]. Our proportion of self-reported GP contacts might be higher as a result of the wording of the questions, different methodological approaches, or because of the changed cultural differences in the arena where people and GPs meet. Current medical practice is characterised by a focus on risk reduction and early detection of illness, which combined with developments in biomedical knowledge and diagnostic technologies has expanded "the pool of potential symptoms" [37]. Thus, more bodily changes, feelings or sensations may be designated as potential signs of disease. It is therefore to be expected that the pool of self-reported symptoms increases, and we may see a higher frequency of healthcare seeking. However, this should be further explored.

The decision on whether to contact a GP is based on a complex mix of physical, psychological and social factors [38]. The same symptom may by some people be regarded as harmless, while others may consider it as being too serious to ignore. The persistence of a symptom may also influence the interpretation of the symptom. These considerations or interpretations of the symptom will affect the decision on whether or not to contact the GP. The key issue seems not always to be the symptom itself.

Early diagnosis and prompt treatment are generally presumed to be a key to a better prognosis of most illnesses. An enhanced understanding of healthcareseeking behaviours may assist health care professionals in identifying patients who are at risk of postponing contact to the GP and may help development of health campaigns targeting these individuals.

The literature indicates that multiple factors may affect peoples' decision to seek healthcare. In this study we focused on prevalence and gender differences with regard to reporting of symptoms and contact to the GP. Future studies should explore other possible factors, which might trigger the individual to contact the GP, including age, characteristics of the symptoms and sociocultural factors such as use of social network in relation to a symptom.

\section{Conclusions}

This study provides a comprehensive overview of the prevalences of 44 different self-reported symptoms and the corresponding proportions of GP contacts in a large nationwide population based study. More than 9 out of 10 individuals reported having experienced at least one symptom and $37 \%$ had contacted the GP with a symptom. For almost $2 / 3$ of the reported symptoms no gender differences were found concerning the proportion leading to GP contacts.

\section{Competing interests}

The authors declare that they have no competing interests. The study is financially supported by the Novo Nordisk Foundation, the Danish Cancer Society and "The Danish Research Centre for Cancer Diagnosis in Primary Care - (CaP)". The funders have not been involved in the design or development of the study.

\section{Authors' contributions}

$\mathrm{SE}, \mathrm{SR}, \mathrm{KB}$ and DJ participated in the design of the study, development of the questionnaire, the logistics concerning the survey and the drafting of the manuscript. SE moreover did the main work in forming the manuscript and carried out the statistical analyses. RSA, AFP, JS, RPS and PV participated in the design of the study, development of the questionnaire and drafting of the manuscript. PVL participated in the development of the questionnaire, drafting of the manuscript and the statistical considerations concerning the survey and analyses. All authors read and approved the final manuscript.

\section{Acknowledgement}

This survey is conducted in collaboration between University of Southern Denmark and Aarhus University.

The project is part of the research portfolio at the Research Centre for Cancer Diagnosis in Primary Care (CaP) and is financially supported by the Novo Nordisk Foundation and the Danish Cancer Society.

The authors would like to thank Lise Keller Stark for proofreading the manuscript.

\section{Author details}

${ }^{1}$ Research Unit of General Practice, Department of Public Health, University of Southern Denmark, J.B. Winsløws Vej 9A, 5000 Odense C, Denmark. ${ }^{2}$ The Research Unit for General Practice, Research Centre for Cancer Diagnosis in Primary Care - CaP, Department of Public Health, Aarhus University,

Bartholins Allé 2, 8000 Aarhus C, Denmark. 
Received: 6 October 2014 Accepted: 7 July 2015

Published online: 21 July 2015

\section{References}

1. Last JMAM. The Iceberg "Completing the clinical picture" in general practice. Lancet. 1963:7297(2):28-31.

2. Dunnell K. Medicine takers and hoarders. J R Coll Gen Pract. 1973;23 Suppl 2:2-9.

3. Svendsen RP, Stovring H, Hansen BL, Kragstrup J, Sondergaard J, Jarbol DE. Prevalence of cancer alarm symptoms: a population-based cross-sectional study. Scand J Prim Health Care. 2010;28(3):132-7.

4. Svendsen RP, Jarbol DE, Larsen PV, Stovring H, Hansen BL, Soendergaard J. Associations between health care seeking and socioeconomic and demographic determinants among people reporting alarm symptoms of cancer: a population-based cross-sectional study. Fam Pract. 2013;30(6):655-65.

5. Verbrugge LM, Ascione FJ. Exploring the iceberg. Common symptoms and how people care for them. Med Care. 1987;25(6):539-69.

6. Hannay D. The symptom iceberg. Br J Gen Pract. 2011;61(584):224.

7. Bruusgaard D, Tschudi-Madsen H, Ihlebaek C, Kamaleri Y, Natvig B. Symptom load and functional status: results from the Ullensaker population study. BMC Public Health. 2012;12:1085.

8. McAteer A, Elliott AM, Hannaford PC. Ascertaining the size of the symptom iceberg in a UK-wide community-based survey. Br J Gen Pract. 2011;61(582):e1-11.

9. Andersen R, Anderson OW, Smedby B. Perception of and response to symptoms of illness in Sweden and the United States. Med Care. 1968;6(1):18-30.

10. Goldberg W, Goldfrank L. The ecology of medical care revisited. N Engl J Med. 2001;345(16):1211.

11. Minassian VA, Yan X, Lichtenfeld MJ, Sun H, Stewart WF. The iceberg of health care utilization in women with urinary incontinence. Int Urogynecol J. 2012;23(8):1087-93.

12. Stoller EP, Forster LE, Portugal S. Self-care responses to symptoms by older people: A health diary study of illness behavior. Med Care. 1993;31(1):24-42.

13. White $\mathrm{KL}$, Williams TF, Greenberg BG. The ecology of medical care. N Engl J Med. 1961;265:885-92.

14. Verbrugge LM. From sneezes to adieux: stages of health for American men and women. Soc Sci Med. 1986;22(11):1195-212.

15. Hunt K, Adamson J, Hewitt C, Nazareth I. Do women consult more than men? A review of gender and consultation for back pain and headache. J Health Serv Res Policy. 2011;16(2):108-17.

16. Barsky AJ. The paradox of health. N Engl J Med. 1988;318(7):414-8.

17. Wyke S, Hunt K, Ford G. Gender differences in consulting a general practitioner for common symptoms of minor illness. Soc Sci Med. 1998;46(7):901-6

18. Hamilton W. The CAPER studies: five case-control studies aimed at identifying and quantifying the risk of cancer in symptomatic primary care patients. Br J Cancer. 2009;101:S80-6.

19. Hvidberg L, Pedersen AF, Wulff CN, Vedsted P. Cancer awareness and socio-economic position: results from a population-based study in Denmark. BMC Cancer. 2014;14:581.

20. Pedersen CB, Gotzsche H, Moller JO, Mortensen PB. The Danish Civil Registration System. A cohort of eight million persons. Dan Med Bull. 2006;53(4):441-9.

21. Rasmussen S, Sondergaard J, Larsen PV, Balasubramaniam K, Elnegaard S, Svendsen RP, et al. The Danish Symptom Cohort: Questionnaire and Feasibility in the Nationwide Study on Symptom Experience and Healthcare-Seeking among 100000 Individuals. Int J Family Med. 2014;2014:187280.

22. Referral guidelines for suspected cancer [http://www.nice.org.uk/guidance/cg27]

23. [CG122] Ovarian cancer: The recognition and initial management of ovarian cancer [http://www.nice.org.uk/Guidance/CG122]

24. Jones R, Latinovic R, Charlton J, Gulliford MC. Alarm symptoms in early diagnosis of cancer in primary care: cohort study using General Practice Research Database. BMJ. 2007;334(7602):1040.

25. Thygesen LC, Daasnes C, Thaulow I, Bronnum-Hansen H. Introduction to Danish (nationwide) registers on health and social issues: structure, access, legislation, and archiving. Scand J Public Health. 2011;39(7 Suppl):12-6.

26. Jensen VM, Rasmussen AW. Danish Education Registers. Scand J Public Health. 2011;39(7 Suppl):91-4
27. Elliott AM, McAteer A, Hannaford PC. Revisiting the symptom iceberg in today's primary care: results from a UK population survey. BMC Fam Pract. 2011;12:16.

28. Rothman KJ, Greenland S, Lash TL. Modern epidemiology: Lippincott Williams \& Wilkins; 2008.

29. McColl E. Best practice in symptom assessment: a review. Gut. 2004;53 Suppl 4:iv49-54.

30. Jenkins P, Earle-Richardson G, Slingerland DT, May J. Time dependent memory decay. Am J Ind Med. 2002;41(2):98-101.

31. Kroenke K, Harris L. Symptoms research: a fertile field. Ann Intern Med 2001;134(9 Pt 2):801-2.

32. Petrie KJ, Faasse K, Crichton F, Grey A. How common are symptoms? Evidence from a New Zealand national telephone survey. BMJ open. 2014;4(6):e005374.

33. Macleod U, Mitchell ED, Burgess C, Macdonald S, Ramirez AJ. Risk factors for delayed presentation and referral of symptomatic cancer: evidence for common cancers. Br J Cancer. 2009;101 Suppl 2:S92-S101.

34. Verbrugge LM. Triggers of symptoms and health care. Soc Sci Med. 1985;20(9):855-76.

35. Hibbard JH, Pope CR. Gender roles, illness orientation and use of medical services. Soc Sci Med. 1983;17(3):129-37.

36. Hannay D, Maddox E. Incongruous referrals. Lancet. 1975;306(7946):1195-7.

37. Rose N. The politics of life itself: Biomedicine, power, and subjectivity in the twenty-first century. Princeton University Press; 2007.

38. Campbell SM, Roland MO. Why do people consult the doctor? Fam Pract. 1996;13(1):75-83.

\section{Submit your next manuscript to BioMed Central and take full advantage of:}

- Convenient online submission

- Thorough peer review

- No space constraints or color figure charges

- Immediate publication on acceptance

- Inclusion in PubMed, CAS, Scopus and Google Scholar

- Research which is freely available for redistribution 